\title{
Public health advice based on routine mumps surveillance in England and Wales
}

C Yung (Chee.Yung@hpa.org.uk) ${ }^{1}$, A Bukasa $^{1}, K_{\text {Krown }}^{1}$, R Pebody ${ }^{1}$

1. Centre for Infections, Health Protection Agency, London, United Kingdom

Citation style for this article:

Yung C, Bukasa A, Brown K, Pebody R. Public health advice based on routine mumps surveillance in England and Wales. Euro Surveill. $2010 ; 15(38):$ pii=19669.

Available online: http://www.eurosurveillance.org/ViewArticle.aspx?Articleld=19669

In view of the increase in the number of mumps cases in 2009 and of the reports of mumps outbreaks in 2010, we report on the most recently available mumps surveillance data in England and Wales.

\section{Background}

Most industrialised countries have had long-standing mumps immunisation programmes. Despite achieving relatively high coverage with one or even two doses of vaccine, several countries, including the United Kingdom (UK), have reported outbreaks of mumps, usually amongst older teenagers in settings such as universities and schools, in recent years [1]. In some outbreaks, populations have been highly vaccinated [2-7].

Several mumps outbreaks have been reported in the UK during 2009-2010. The UK introduced a mumps vaccine with the start of the single-dose measles-mumps-rubella (MMR) programme in 1988. There was, however, a large outbreak of mumps in 2005 in England and Wales mainly affecting individuals aged between 18 and 24 years who were not eligible for routine MMR vaccination, but who had also had minimal exposure to mumps during childhood due to the reduction in number of cases following the introduction of the MMR vaccine programme [2]. There were 43,378 confirmed mumps cases in 2005. Although there was a subsequent decline in case numbers for a couple of years, the number of confirmed mumps cases started to increase again in 2008 and a further increase was observed in 2009, with cases again mainly occurring in school or college settings where there is high potential for transmission due to close contact. This alone is, however, unlikely to be the sole reason for the current increase in mumps cases. Increasingly, mumps outbreaks in populations with high vaccination coverage are being reported [3-6]. Waning immunity leading

\section{FIGURE 1}

Age-specific clinical notifications of mumps cases (five-week moving averages), England and Wales, week 11995 week 332010

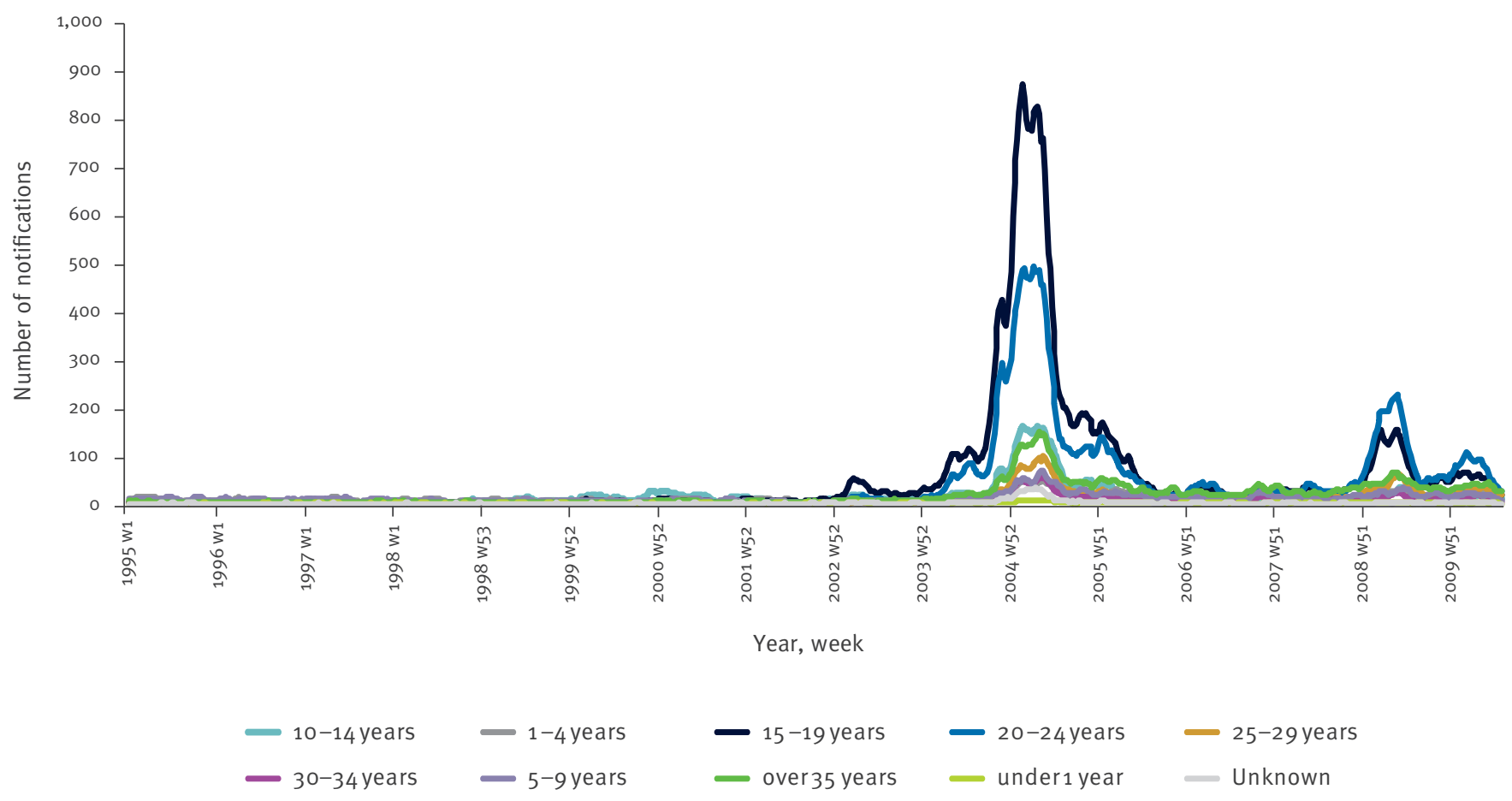


to secondary vaccine failure is likely to contribute to these outbreaks $[7,8]$.

\section{Methods}

In England and Wales, mumps is a notifiable disease and hence must be reported to the appropriate officer (an official working in the local health authority). Following notification of a suspected case, a confirmatory oral fluid testing kit is sent out to the patient's general practitioner. Vaccination status is requested on the sample form. All oral fluid samples are tested in the Immunisation and Diagnosis Unit, Virus Reference Laboratory, Centre for Infections, Health Protection Agency (HPA), London. Once cases are laboratory confirmed, an enhanced surveillance form is sent out to request further epidemiological data, including confirmation of vaccination status and number of doses administered. The system is based on a voluntary return of surveillance forms, with a return rate greater than $50 \%$.

Mumps vaccination status combines information from both the sample request form and the enhanced surveillance of laboratory-confirmed cases. A case with no documented evidence from either source as being vaccinated is assumed to be unvaccinated ( $27 \%$ of cases had unknown mumps vaccination status).

\section{Results}

Following a large outbreak in 2004 and 2005, there has been a further increase in mumps cases in 2008 and 2009 (Figure 1). During the first quarter of 2010, there was a small increase in notifications of mumps by clinicians compared with the previous quarter in 2009 ( 3,786 versus 3,009 cases). There is now a downward trend in the second quarter of 2010 (Figure 1 and 2).

\section{FIGURE 2}

Age and MMR vaccination status of laboratory-confirmed mumps cases, England and Wales, Quarter 1 and Quarter $2,2010(n=2,680)$

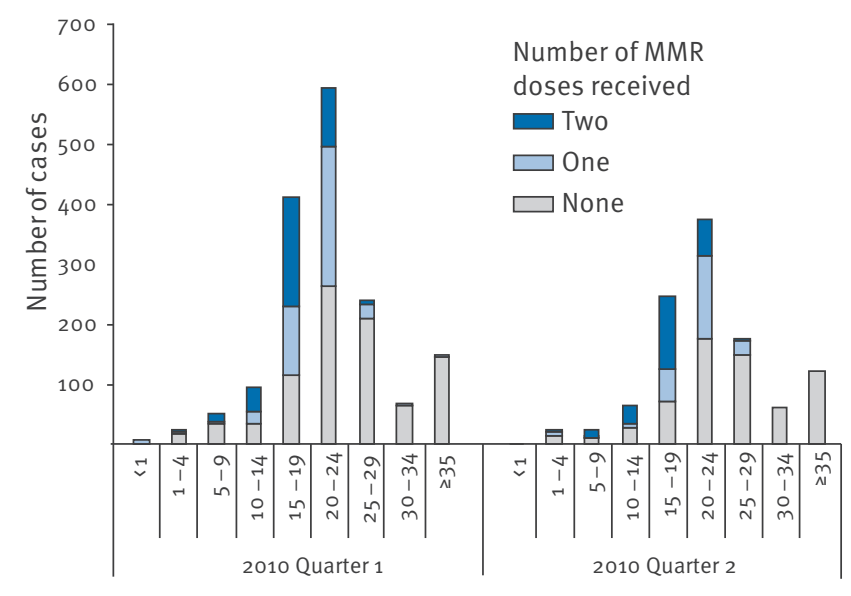

Year and quarter, by age group (years)

MMR: measles-mumps-rubella.
Laboratory data also show a similar downward trend, with 1,074 cases in the second quarter of 2010 compared with 1,606 cases in the first. This compares with 1,691 and 3,271 laboratory-confirmed cases in the first and second quarters of 2009 respectively.

Analysis of confirmed mumps cases in the first half of 2010 shows that the 20-24-year age group is most affected (35.9\%; 962 of 2,680 cases) followed by the 15-19-year-olds (24.4\%; 654 of 2,680 cases) (Figure 2). There were slightly more male $(51.5 \%)$ than female cases $(47.6 \%)$.

In both age groups with the highest number of cases (cases aged $15-24$ years), only $28.8 \%(n=466)$ of 1,616 cases had received two doses of MMR vaccine. In total, the majority of all confirmed cases being reported were still either unvaccinated $(55.3 \% ; 1,481$ of 2,680$)$ or had received only one dose of MMR vaccine (23.3\%; 625 of 2,680 ).

\section{Discussion}

There was an increase in the number of mumps cases in the first quarter of 2010 compared with the final quarter in 2009, but this increase did not continue into the second quarter. The number of confirmed mumps cases for the first six months of 2010 (2,680 cases) was much lower than in the same period of last year, when there had been a steep increase (4,962 cases). The observed increase in the number of confirmed cases of mumps in 2009 and 2010 had not been seen in the three preceding years.

The main limitation of analysing confirmed cases in a timely manner is that delays in receipt of samples or testing could result in underestimation of cases. However, clinical notifications, which though less specific, do reveal a trend in a timely manner, which can help in the interpretation of confirmed cases. The fall in clinical notifications of mumps cases in the second quarter of 2010 suggests that the similarly lower number of confirmed cases in this period is a real effect and is not due to the inherent reporting delays. The other possible limitation is the assumption that cases with missing vaccination status are unvaccinated, which could potentially overestimate the proportion of cases that are unvaccinated. However, we think this is unlikely, as the proportion of cases with missing vaccination status is not different by either age or region compared with those with known vaccination status.

It is clear from the data presented that the surge in mumps cases following clusters in educational settings in the early half of 2009 did not occur in 2010. As we now move from the third quarter and school summer holidays, we are not expecting this situation to change.

The majority of mumps cases are from the 15-24-year age group: the majority of cases in this age cohort had received either no MMR vaccine or only one dose. Most of the 15-19-year age group would have been eligible 
to receive two doses MMR vaccine. The 20-24-year age group was eligible for one dose of MMR but is unlikely to have received the second dose of MMR, which was only introduced in the UK in 1996. The recommended schedule to ensure optimum protection against mumps is two doses of MMR vaccine. It thus remains important to ensure that all individuals, in particular school leavers and those at highest risk aged between 15 and 24 years, have two documented doses of MMR vaccine. Any opportunity to check this should be undertaken to reduce the likelihood of another increase in mumps cases in the future - in particular this can be done at school leaving and also entry into college, university or other higher education institutions. The same rationale should be applied in other European settings.

\section{References}

1. Health Protection Agency (HPA). Laboratory confirmed number of mumps cases in England and Wales: update to end-

November 2009. Health Protection Report. 4(2);15 Jan 2010. London: HPA; 2010. Available from: http://www.hpa.org.uk/ hpr/archives/2010/news0210.htm\#mmps

2. Savage E, Ramsay M, White J, Beard S, Lawson H, Hunjan R, et al. Mumps outbreaks across England and Wales in 2004: observational study. BMJ. 2005;330(7500):1119-20.

3. Dayan GH, Quinlisk MP, Parker AA, Barskey AE, Harris ML, Schwartz JM, et al. Recent resurgence of mumps in the United States. N Engl J Med. 2008;358(15):1580-9.

4. Marin M, Quinlisk P, Shimabukuro T, Sawhney C, Brown $C$, Lebaron CW. Mumps vaccination coverage and vaccine effectiveness in a large outbreak among college students-lowa, 2006. Vaccine. 2008;26(29-30):3601-7.

5. Centers for Disease Control and Prevention (CDC).Update: mumps outbreak - New York and New Jersey, June 2009-January 2010. MMWR Morb Mortal Wkly Rep. 2010;59(5):1259. Available from: http://www.cdc.gov/mmwr/preview/ mmwrhtml/mm5905a1.htm

6. Boxall N, Kubinyiova M, Prikazsky V, Benes C, Castkova J. An increase in the number of mumps cases in the Czech Republic, 2005-2006. Euro Surveill. 2008;13(16). pii: 18842. Available from: http://www.eurosurveillance.org/ViewArticle. aspx?Articleld $=18842$

7. Cohen C, White JM, Savage EJ, Glynn JR, Choi Y, Andrews N, et al. Vaccine effectiveness estimates, 2004-2005 mumps outbreak, England. Emerg Infect Dis. 2007;13(1):12-7.

8. Cortese MM, Jordan HT, Curns AT, Quinlan PA, Ens KA, Denning PM, et al. Mumps vaccine performance among university students during a mumps outbreak. Clin Infect Dis. 2008;46(8):1172-80. 